\title{
LUGAR ONDE SE PENSAM AS IDEIAS E SE ESCREVE SOBRE ELAS: MEMÓRIA - HISTÓRIA DO NEPEC (1993-2013)
}

- ZENY ROSENDAHL ${ }^{1}$

Resumo: 0 artigo faz um resgate da memória e da história do Núcleo de Estudos e Pesquisas sobre Espaço e Cultura, o NEPEC, atuante no Instituto de Geografia da Universidade do Estado do Rio de Janeiro, fazendo um balanço de sua atuação desde 1993, quando foi criado. 0 artigo destaca três importantes contribuições do NEPEC para a geografia brasileira: seu pioneirismo no desenvolvimento de estudos e pesquisas sobre a religião no espaço, seu papel de centro de divulgação da geografia cultural internacional e seu lugar de difusão da geografia cultural nacional.

Palavras-chave: Geografia Cultural brasileira; NEPEC, História; Memória.

Ando devagar, porque já tive pressa, e Levo este sorriso, porque já chorei demais, Hoje me sinto mais forte, mais feliz quem sabe, Só levo a certeza, de que muito pouco eu sei,

Ou nada eu sei,

Conhecer as manhas e as manhãs,

O sabor das massas e das maçãs, É preciso amor pra poder pulsar, É preciso paz pra poder sorrir, É preciso a chuva para florir,

Penso que cumprir a vida, seja simplesmente, Compreender a marcha, e ir tocando em frente (.... .)

Todo mundo ama um dia, todo mundo chora, Um dia a gente chega, no outro vai embora, Cada um de nós compóe a sua história, cada ser em si, carrega o dom de ser capaz, de ser feliz! 
A letra da música "Tocando em frente", de Almir Satter e Renato Teixeira, fornece o cenário do dia a dia. Do sentido de ir andando em suas ações, já priorizadas e seguras em sua importância para aquele que fez a escolha da caminhada. A poesia fala de compreender essa marcha escolhida; é, de certa maneira, a seleção de como você carrega sua filosofia de vida. A história de vida que o Núcleo de Estudos e Pesquisas sobre Espaço e Cultura (NEPEC) carrega possui um caminhar de "tocando em frente", com raízes na instituição universitária, no pensar social da importância dos estudos para a sociedade, e na caminhada do próprio NEPEC, sem dúvida, em prosa e verso, ao fazer ciência.

Ao compor a memória do núcleo e ressaltar sua contribuição na geografia na UERJ (Universidade do Estado do Rio de Janeiro), iremos enfatizar a difusão da geografia cultural. Denominamos o núcleo como o lugar onde se pensam as ideias e se escreve sobre elas. Este lugar vem fazendo a história da geografia cultural no Brasil, desde 1993, ano de sua criação, e, como tal, vem impregnado de emoções variadas e conflitantes nesses 20 anos em que se consolidou como receptáculo das ideias. Tais ideias estão contidas em dois caminhos principais, ao longo dos quais as pesquisas em geografia cultural foram ampliadas.

Ambos distinguem-se entre si, sobretudo pela gênese e pela repercussão de cada um dos caminhos, bem como pelo conceito de cultura adotado. Geografia Cultural saueriana ou Escola de Berkeley e Nova Geografia Cultural ou
Geografia Cultural pós-80 designam os dois caminhos do nosso "tocando em frente" pensando as ideias e escrevendo sobre elas no NEPEC.

Duas perguntas se destacam neste momento de celebração de 20 anos do NEPEC, já fortalecido na ciência geográfica brasileira: Como a localização do NEPEC, na UERJ, influenciou na visibilidade da geografia cultural? E quais as principais ideias sustentadas pelo grupo inicial de pesquisadores?

Queremos responder, neste artigo, como as posições das pessoas, dos objetos, das coisas dentro daquilo que chamamos de "trama locacional consistem em um elemento central, no exame do fenômeno da visibilidade" (GOMES, 2013， p.36), levando-se em consideração as "lições da historiografia da ciência" (BERDOULAY, 2003). O geógrafo Vincent Berdoulay enfatiza a importância de se considerar o desenvolvimento contínuo da ciência, pela acumulação de fatos, de descobertas e de conhecimento científico. Em comunhão com estas ideias, iremos privilegiar "o contexto histórico e as ambiências intelectuais na evolução" (BERDOULAY, 2003, p. 47) da geografia cultural no Brasil.

Ao rememorar os acontecimentos do passado recente, num relato de 20 anos de NEPEC, estamos privilegiando a memória particular do autor, que o escreve, mas também a memória-história dos grupos envolvidos na narrativa. Trata-se de lembranças que carrego em mim, mas sempre interagidas com o grupo social, com a instituição e com a sociedade. Foi 
neste contexto temporal que as relações ocorreram (Maurice Halbwachs, 1950).

O conceito de memória e memóriahistória tem $\mathrm{o}$ aspecto fundamental de compreensão em sua relação com o lugar. Lieu de mémoire, conceito criado por Pierre Nora (1984) ao valorizar o espaço e o tempo do acontecido, será utilizado neste texto. Lugar e vida são os elementos que compõem a memória. A identidade de distinção e de pertencimento de um grupo com a instituição acadêmica à qual pertence, numa constante descoberta dos fenômenos, envolvem a memória-história. Ampliando as ideias, o NEPEC possui as qualidades ressaltadas pelo Nora (1984): possui um lugar fixo, um valor simbólico forte, uma prática de ritos acadêmicos e uma função definida. Sendo assim, o recordar será a memória da história dos acontecimentos, dos fatos envolvendo, às vezes, o período anterior a sua fundação em 1993.

Ao tecer alguns comentários sobre a história do NEPEC, desejamos retratar não só as atividades acadêmicas do núcleo, mas, também, a sua criação no Departamento de Geografia, tempo e lugar que ocupa na UERJ. A finalidade é iniciar a memória do NEPEC na importância da informação do pretérito, ao lembrar o que aconteceu antes e as decisões no presente como forma de registro da memória individual. A valorização da informação, segundo o pensar de Le Goff (1990), qualifica o registro do acontecido e permite a conservação para o tempo futuro. A comemoração dos 20 anos merece tal documento.
Tratar sobre memória exige o relato de fatos históricos compartilhados com o grupo, de abordagens psicológicas e do ponto de vista do informante. A expressão ponto de vista é proposta por Paulo Cesar da Costa Gomes em um "sentido mais concreto para designar lugares" (GOMES, 2003, p. 19) e será com este sentido que daremos nossa opinião. Vamos além, pois, estando eu numa posição interna privilegiada, vejo referências que não veria se estivesse em posição externa ao NEPEC. No desejo de compartilhar a memória-história do núcleo neste artigo e no fôlego de rememorar os fatos, estarei, sem dúvida, revelando quem somos.

Nasci no final da $2^{\circ}$ Grande Guerra, no início da primavera no Brasil. Sou filha de imigrantes da Dinamarca - Bjorn Sylvester Rosendahl - e de Portugal - Maria Rosendahl. Como estudante brasileira, represento o "resultado da Reforma Capanema na Educação", com a vida social dos "anos dourados", já no seu final da década de 50, ou melhor, os "anos dourados" no Instituto de Educação, na cidade do Rio de Janeiro.

$\mathrm{Na}$ segunda metade dos anos 60, teve início a minha vida universitária, na Graduação em Geografia. O curso estava vinculado à então UEG - Universidade do Estado da Guanabara. Este início ocorreu no prédio localizado na Rua Haddock Lobo, vizinho, hoje, ao Colégio Bradesco, no bairro da Tijuca. Em seguida, o Curso de Geografia foi transferido de lugar, para o prédio na Rua Fonseca Telles, no Bairro de São Cristóvão. No ano de conclusão do 
curso universitário, em 1970, nova mudança de lugar ocorreu: fomos inaugurar o único prédio construído no Campus do Maracanã. Este prédio é o Haroldo Lisboa da Cunha. Hoje é ele conhecido, na comunicação do dia a dia na UERJ, como o prédio do Haroldinho, apelido aceito em relação à altura do prédio, que é inferior em comparação aos prédios do Pavilhão João Lira.

Não há dúvida de que o currículo em vigor na UEG, no período de 1970 a 1997, não poderá ser comparado com os que temos hoje em nossas disciplinas. As lembranças, que continuam com admiração, desse tempo são das aulas e das orientações do Professor Maurício Silva Santos. Na ocasião, ganhei dele um livro de presente: Rencontres de la géographie et de la sociologie, de Max Sorre (1957). Não saberia explicar o principal motivo de tê-lo recebido, apenas reconheço que os estudos de Sorre inscrevem-se nos que dominam o final da primeira metade do século XX. O apaixonante da leitura de Sorre era sua abordagem das atividades religiosas, ideias contidas neste livro. Ele indica dois caminhos de análise: a interpretação como atividade de antecedência e como atividade de consequência.

$\mathrm{Na}$ primeira, o fato religioso ocorre desde os primórdios da humanidade e possui influência na cultura do grupo; na segunda, as atividades humanas religiosas se explicam como produto da ocorrência do fato religioso no espaço. O simbolismo das formas espaciais e suas práticas religiosas vivenciadas não eram considerados nas interpretações. As manifestações da consciência individual não são consideradas aqui, pois refletem as tendências, as necessidades e os interesses psicológicos, elementos que possuem significado na nova geografia cultural ou geografia cultural pós-80 (ROSENDAHL, 2013, p. 106).

Cursei a Graduação, de 1967 a 1970, no regime ditatorial militar. Durante este período, tínhamos, entre as atividades "subversivas" realizadas no Centro Acadêmico, localizado no Prédio do Fonseca Telles, as leituras escondidas, como, por exemplo, Le Livre Rouge - Citations du President Mao TseToung. Nesta época, muitos universitários atuavam em grupos religiosos, em organizações cristãs como JEC (Juventude Estudantil Católica), JUC (Juventude Universitária Católica), pelo lado das igrejas católicas, e, na vertente das igrejas protestantes, havia a União Cristã dos Estudantes do Brasil. As reuniões priorizavam as questões sócio-políticas do momento.

O meu retorno à UERJ, como professora, ocorreu em 1980, ainda no período ditatorial, porém após a promulgação da Lei da Anistia, ocorrida em 1979 no país. Ao relembrar a situação para compor o artigo, as lembranças representam um repensar as ideias de hoje com a experiência do passado, no lugar, no lieux de mémoire.

Essas questões que envolvem o pesquisador e a sociedade tornam-se importantes no contexto da pesquisa: são "as ideias de geógrafos que parecem isolados, mas cujo círculo de afinidades é muito revelador 
$(\ldots)^{\prime \prime}$; o que é

"significativo para se compreender $\quad \mathrm{o} \quad$ seu pensamento geográfico não é tanto a sua falta de contato com uma comunidade de geógrafos, mas as inclinações ideológicas que os colocam em contato com não geógrafos" (BERDOULAY, 2003, p. 52)

Comungo com essa regra básica de metodologia historiográfica, bem como outra que afirma ser fundamental o círculo de afinidades, que abrange mais do que uma comunidade científica, uma vez que inclui as diversas indagações sobre as questões sociais em pauta no período escolhido para a nossa análise. Meu retorno à UERJ, em 1980, ocorreu no ISEB - Instituto Superior de Estudos Brasileiros, localizado no Centro de Ciências Sociais. Era um instituto que possuía grupos de pesquisa interdisciplinar em diferentes áreas do conhecimento. $\mathrm{O}$ grupo de pesquisa de que eu participava concentrava seus encontros de reflexão teórica na temática da religião na sociedade, com os cientistas: Pedro de Assis Ribeiro de Oliveira (Doutor em Sociologia. Université Catholique de Louvain - França); José Flavio Pessoa de Barros (Doutor em Antropologia. Universidade de São Paulo); Creusa Capalbo (Doutor em Filosofia Université Catholique de Louvain - França) e o Leonardo Boff (Doutor em Teologia e Filosofia na Universidade de Munique - Alemanha). 
resultaram nas minhas atuais convicções sobre a forte influência do poder religioso na sociedade.

As análises conclusivas apresentavam uma resistência forte e constante, por parte dos grupos étnico-religiosos, a qualquer implantação de práticas relacionadas às teorias da dinâmica populacional de planejamento familiar no país. A minoria, no entanto, aceitava conhecer a temática do aborto, da sexualidade, da pílula feminina, da pílula masculina, principalmente. Acrescento que a conjuntura de mudança e renovação do comportamento mundial já tinha chegado ao Brasil neste período. Os estudos que eu desejava realizar sobre a mulher, a família, a paternidade responsável não encontravam diálogos fora das universidades.

O meu campo empírico para a pesquisa estava bastante prejudicado. Assim, dediqueime aos estudos dos fatores que impediam os debates nos assuntos de religião e comportamento humano. Era necessário voltar para o plano teórico e, então, resolvi me matricular para fazer doutorado, escolhendo a USP - Universidade de São Paulo.

Em 1989, na USP, eu iniciava a tese de doutorado na temática da religião. Em maio de 1994, terminei o doutorado. Defendi a tese intitulada Porto das Caixas: O Espaço Sagrado da Baixada Fluminense, tendo como orientador o Prof. Heinz Dieter Heidemann.

Minha permanência na USP foi, em maior parte do período, no CERU - Centro de Estudos Rurais e Urbanos, com os professores de Sociologia e Antropologia da Religião da USP. Este núcleo foi o lugar das trocas de ideias, das leituras e do acolhimento vivenciado por mim na estrutura uspiana durante os anos de 1989 a 1993. Foi o elo entre as disciplinas do saber a religião como ciência, cursadas no Departamento de Sociologia da USP e no ISER (Instituto de Estudos da Religião) (RJ), e as disciplinas do pensar geograficamente, cursadas na Geografia da USP e na UFRJ (Universidade Federal do Rio de Janeiro) com o professor Roberto Lobato Azevedo Corrêa. Cursei, sem dúvida, um doutorado interdisciplinar e interinstitucional. Nasceu dessa influência de saber, dessas convergências de ideias, o meu compromisso de reproduzir um lugar semelhante de viver e sentir as novas reflexões e sua localização estava decidida: tinha de ser na Geografia da UERJ, e, assim, o foi feito.

$$
\text { Estas conclusões ratificaram a }
$$
importância de meus estudos de religião em geografia, muitas vezes contraditórios, um intenso apego à materialidade e uma verdadeira ânsia do sagrado. $\mathrm{O}$ meu desejo foi contribuir para o preenchimento de uma enorme lacuna, tanto na bibliografia em geografia dos estudos sobre religião, como dos ensaios no campo da geografia. Ao apostar na interseção destas duas abordagens, foi resgatada uma dimensão fundamental, e injustamente esquecida: a da religião como fenômeno da cultura e da sociedade - a sua dimensão espacial. Este combinado propiciou projetos que foram realizados na Geografia da UERJ.

A geografia chega ao século XXI dedicando-se cada vez mais à compreensão das dimensões política e religiosa do espaço, que 
podem ser analisadas segundo vários aspectos.

Privilegiamos um tipo particular de hierocracia - o poder do sagrado - sobre o comportamento do homem no espaço.

O conceito de cultura, na segunda metade do século $\mathrm{XX}$, coexiste com o uso antropológico, sociológico e geográfico para indicar o modo de vida global de determinado povo ou de grupo social. Williams (2008) reconhece a dificuldade da compreensão do termo - cultura - e destaca duas formas principais de interpretação: "(a) ênfase no espírito formador de um modo de vida global, manifesto por todo o âmbito das atividades sociais, porém mais evidente em "atividades culturais" (WILLIAMS, 2008, p. 11); e a segunda forma, (b) ênfase em uma ordem social global no seio da qual uma cultura específica, quando a estilos de arte e tipos de trabalho intelectual." (WILLIAMS, 2008, p. 12). Neste pensar, o autor diz: "é considerada produto direto ou indireto de uma ordem primordialmente constituída por outras atividades sociais.". (WILLIAMS, 2008, p. 1112).

As ciências, notadamente a Sociologia da Cultura, acompanham, na segunda metade do século $\mathrm{XX}$, as atividades desenvolvidas a partir dessas duas posições.

\section{Superação de dificuldades}

A difusão do conhecimento e a disciplina "Geografia e Religião" realizavam-se, na UERJ, antes do ano de 1994. Ao elaborarmos um novo currículo, referente a este ano, a disciplina "Geografia da Religião" estava incluída com intensa participação dos alunos. A barreira inicial criada por aqueles que desconheciam o novo pensar em geografia foi vencida e teve o apoio, sem dúvida, dos alunos envolvidos no novo conhecimento. O currículo implantado colocava a Geografia da UERJ na vanguarda da temática da cultura em sua abordagem espacial no Rio de Janeiro e nas demais universidades brasileiras.

O Núcleo de Estudos e Pesquisas sobre Espaço e Cultura foi criado em novembro de 1993. É um local onde fluem as ideias e se escreve sobre elas (Rosendahl, 2012). As condições eram favoráveis às pesquisas científicas na UERJ. Os fatores internos ao desenvolvimento da ciência geográfica, na instituição, não criaram barreiras ou limitaram este crescimento. A instituição - UERJ incentiva a inovação de pesquisa em diversas áreas, desde as facilidades à especialização na docência à abertura da iniciação à pesquisa para os discentes.

O NEPEC é um lugar pequeno, porém de função ativa como centro de produção e difusão da geografia cultural no Brasil. Penso que o lugar é importante para criar. $\mathrm{O}$ ambiente é parte integrante desse sucesso. O professor Roberto Lobato Azevedo Corrêa foi parceiro intelectual desde 1993 nas atividades nepequeanas. Suas pesquisas orientam-se em três direções: relação entre espaço e religião, espaço e simbolismo e cultura popular. A 
ênfase, contudo, fixou-se na primeira das três temáticas. A preocupação foi sempre apresentar uma clara e sólida visão geográfica de suas marcas impressas no espaço. Hoje, a temática firma-se ao oferecer novas trilhas para a geografia brasileira. Acrescento que, nesses 20 anos, estive sempre cercada de companheiros, colaboradores, bolsistas, alunos e amigos. Somando a coragem e a dedicação, completamse os fatores que me auxiliaram no sucesso do NEPEC. O processo de difusão do conhecimento na geografia cultural no Brasil está consolidado no pensamento. Orgulho-me de ter conduzido o NEPEC nesse processo. Ou melhor dizendo, tocando em frente!

O lugar de atendimento aos alunos comunga com o espaço de confecção do periódico denominado ESPAÇO e CULTURA. Criado em 1995, com dois números por ano, vem sendo o instrumento de divulgação da produção do NEPEC e de outros geógrafos. De seu Conselho Consultivo, fazem parte, entre outros, Marvin Mikesell, Paul Claval, representando, respectivamente, a perspectiva saueriana, a denominada Nova Geografia Cultural, e a visão francesa em Geografia Cultural. O teólogo Leonardo Boff (Teologia da Libertação) e Pedro de Assis Ribeiro de Oliveira (Sociologia da Religião) também são membros desse Conselho - para mais detalhes, consultar Corrêa e Rosendahl (2003). Estou na gestão como Editor-Chefe da revista até hoje e o sucesso da publicação pode ser reconhecido em sua classificação como revista B1, na avaliação Qualis da CAPES.
As principais dificuldades que foram superadas estão ligadas à falta de infraestrutura, tanto de pessoal como de investimentos durante todos esses anos. Essas dificuldades foram vencidas com o apoio da FAPERJ e do CNPq. Os projetos enviados e aceitos pelas instituições de fomento contribuíram, e muito, na continuidade das pesquisas. Ao privilegiar a cultura e geografia nos estudos e atendendo ao rigor metodológico exigido pela ciência, optamos por estabelecer uma sólida base teórica na geografia cultural brasileira.

As reflexões não foram fáceis e as respostas seguiram trilhas nem sempre lineares. A incorporação de novos conhecimentos ocorreram com intensidade maior e mais abrangente durante as atividades realizadas na fase de pós-doutorado, 1997 e 1998, no Institut de Géographie de l'Université Paris-Sorbonne (Paris IV).

Minha permanência na França foi fundamental para assimilar os diversos ritmos dos estudos das relações entre a geografia e a religião. A pesquisa empírica alemã e inglesa veio completar o saber já acumulado por mim durante o pós-doutorado. O desafio continuava.

Os conceitos e as dimensões de análise da cultura em sua espacialidade deveriam ser apresentados à comunidade universitária. A publicação de livros intitulada Coleção Geografia Cultural tem tido uma difusão bem mais ampla que o periódico. As traduções, como estratégias de difusão do conhecimento, foram as trilhas percorridas pelos organizadores nas publicações e vêm atingido os seus objetivos 
desde o aparecimento do primeiro livro, em 1996, intitulado Geografia e Religião: dimensões de análise, EdUERJ. São, em números, 24 os livros que compõem a Coleção Geografia Cultural, da Editora EdUERJ. Os volumes já publicados contemplam, de um lado, trabalhos dedicados à temática da geografia cultural, produzidos por geógrafos brasileiros, e, de outro, transcrições de artigos de um mesmo autor, reunidos para constituir um dos volumes da Coleção, fornecendo um panorama sobre sua contribuição. Como exemplo, tem-se Geografia Cultural: uma antologia, publicado em dois volumes (2012 e 2013).

O desejo de difusão das ideias ocorreu além dos livros da Coleção Geografia Cultural e do Periódico Espaço e Cultura, na realização dos sucessivos simpósios com identidades fortes no mesmo lugar, o auditório 11 - na UERJ, em 1998, 2000, 2002, 2004，2006，2008，2010 e 2012. Com temas novos e diversos, os simpósios envolveram pesquisadores de várias regiões do Brasil, cada um com aproximadamente vinte papers e a participação de cento e vinte a duzentos e quarenta pessoas.

A expansão da geografia cultural no Brasil fez com que, em 2003, a Internacional Geographical Union (IGU) organizasse, por intermédio do Working Group of Cultural Approach in Geography, presidido por Paul Claval, uma Conferência Regional sobre a Dimensão Histórica da Cultura. Assim, em 2003, em dez anos de existência do NEPEC, a geografia cultural estava bem no cenário nacional, pois a realização do Encontro da IGU ocorreu na cidade do Rio de Janeiro e reuniu cerca de cem papers apresentados, dos quais sessenta eram de autores brasileiros.

$\mathrm{Na}$ preocupação constante de divulgação das ideias, em 2003, o NEPEC lança outra publicação - NEPEC TEXTOS -, produção artesanal e destinada à difusão de suas próprias pesquisas, as quais estão fortemente focalizadas nas relações entre espaço e religião.

Hoje, há vários núcleos de estudos com atividades acadêmicas em instituições universitárias que têm um programa de pósgraduação e suas produções estão comentadas em Corrêa e Rosendahl (2003). Podemos afirmar que possuem sua gênese na difusão das ideias provocadas pelo NEPEC. São núcleos que adotaram as informações em espaços acadêmicos com funções diferenciadas no que se refere aos temas e em períodos diferentes.

$\mathrm{Na}$ intenção de informar melhor o contexto do desenvolvimento das ideias nepequeanas e a compreensão da história da geografia cultural na UERJ, utilizaremos as lições da historiografia da ciência sugeridas por Berdoulay (2003). Vincent Berdoulay apresenta as tendências mais relevantes de uma abordagem contextual, destacando inicialmente o "papel do Zeitgeist, considerado como determinante da maneira como cientistas e intelectuais veem e lidam com o mundo." (2003, p. 49).

Devemos reconhecer a UERJ como o lugar que possui diferentes e diversos cientistas e, ao falar da memória do NEPEC, a prioridade é relatar as ideologias defendidas por estes 
intelectuais, pois eles são a própria instituição.

Mais importante ainda é perceber que quase todos os intelectuais envolvidos no ciclo de afinidades, mencionados no período de 1982 a 1989, conforme relatado anteriormente, fazem parte, no tempo presente, do Conselho Editorial da Revista Espaço e Cultura, publicação contínua do NEPEC.

O ciclo das afinidades é um dentre outros dos princípios básicos da metodologia historiográfica elaborados por Berdoulay. O princípio da abordagem contextual consiste "menos em examinar a possível influência de uma ideia do que em verificar as razões que estão por trás da demanda ou uso dessa ideia." (BERDOULAY, 2003, p. 52).

Nesta abordagem contextual, a vontade de estudar a dimensão espacial da religião, no doutorado, na USP, e a criação do NEPEC, ao retornar à Geografia da UERJ, não eram uma ideia nova ou inovadora, apenas uma ideia sustentada por um indivíduo em contexto interno, mas que, no contexto externo, significava uma contribuição criativa e inovadora.

É necessário dar informações dos diversos fatores que, armazenados, retratam o pensar da instituição UERJ, da época em que estão inseridas as atividades do NEPEC, bem como as reflexões geográficas externas ao Brasil nos grupos de estudos em geografia no espaço e tempo. Cosgrove (1999) diz que a geografia cultural possui uma abordagem cultural relacionada com o tempo, o tempo flexível e não tão linear o qual estamos acostumados a reconhecer nos estudos acadêmicos.

A memória-história completa-se ao relatarmos os fatores externos existentes e superados nesses 20 anos. Os fatores externos podem ser colocados em dois pontos. O primeiro está relacionado com a descontinuidade dos estudos da abordagem cultural no Brasil, notadamente os estudos de religião, entre os geógrafos. Na USP, a tese de Maria Cecília França, intitulada Pequenos Centros Paulistas de Função Religiosa, data de 1972. Após 1972, inicia-se um hiato fortemente marcado pela ausência de análise do fenômeno religioso e sua espacialidade. Em 1994, quase vinte anos depois das reflexões de Maria Cecília França, surgiu outro estudo de doutorado, na USP, iniciado em 1989 e que culminou com a tese sobre Porto das Caixas, um centro de peregrinação do catolicismo popular na Baixada Fluminense da geógrafa Rosendahl. Trata-se de uma clara visão do sagrado e sua lógica espacial na geografia cultural pós-80 no Brasil.

Esta descontinuidade que marca os estudos de religião no Brasil não ocorre em outros países, como, por exemplo, em pesquisas de geógrafos alemães. Esta ausência está registrada nas publicações de geógrafos brasileiros. Minhas reflexões, entretanto, são publicadas na Alemanha: Le pouvoir du sacré sur l'espace (BÜTTNER, 1994). Tal publicação, anterior à defesa de doutorado, apresenta análise de dois pequenos centros de convergência religiosa na área rural do Brasil: Muquém, em Goiás, e Santa Cruz dos Milagres, 
no Piauí. A publicação de um artigo e o aceite das ideias surgiram de fora do Brasil. Aqui, os editores de periódicos recebiam o novo com fortes tensões negativas. Já nas publicações organizadas por Manfred Büttner, na temática da religião, tem-se um livro específico e já no décimo volume, o que demonstra um tempo bem maior dedicado à pesquisa. No Brasil, a temática não aparece nas publicações nacionais e representa uma lacuna desconhecida pelo grupo acadêmico formador da barreira do não aceito. A superação foi alcançada já em 1998, por ocasião do $1^{\text {a }}$ Simpósio de Espaço e Cultura na UERJ. Este encontro foi um sucesso de ideias e de público. Imprimiu, sem dúvida, o caminho da geografia cultural no Brasil.

O segundo fator externo selecionado em nossa análise deve ser relacionado às

$$
\begin{aligned}
& \text { "principais questões que } \\
& \text { envolvem uma sociedade, } \\
& \text { mesmo que algumas delas não } \\
& \text { pareçam, à primeira vista, ter } \\
& \text { influenciado a evolução de } \\
& \text { ideias geográficas" } \\
& \text { (BERDOULAY, 2003, p. } \\
& \text { 52). }
\end{aligned}
$$

É necessário identificar, num estudo aprofundado, o fenômeno da religião numa sociedade em mudança, e não atribuir a negligência da temática ao poder e domínio de um pensar ciência em outra corrente na história do pensamento geográfico, isto é, refletir apenas em indagações vinculadas às três matrizes do pensar geografia que predominaram nas décadas de 1970 e 1980.
Tentar resgatar os motivos dessas indagações dos estudos da religião no Brasil, colocando a força das três grandes matrizes do pensamento geográfico, é justificável, mas não é simples (ROSENDAHL, 1996). Pelo relato acima, a religião, como fenômeno cultural, esteve presente na Instituição Alemã durante a influência das tais correntes do pensar geografia. Aqui se percebe a importância da memória institucional, no tempo, tanto na UERJ (Brasil) como em Bochum, na Alemanha.

Havia uma resistência ao estudo da religião a despeito da heterogeneidade cultural do Brasil. A religião era citada nos estudos regionais e não analisada em sua espacialidade. A partir da década de 1980, a geografia da religião se desenvolve com estudos na geografia alemã, inglesa e francesa, conforme as publicações de Büttner (1985), Rinschede (1985), Bonnemaison (1981), Claval (1991), Tanaka (1981) e Sopher (1967).

Havia portas abertas à abordagem cultural em geografia. A pesquisa em religião foi apresentada na década de 80 e, por muito tempo, permaneceu desconhecida dos programas de pós-graduação em geografia, no Brasil. O trabalho de Maria Cecília França e a biblioteca particular do professor-orientador Heinz Dieter Heidemann, ambos professores na USP, concentravam este conhecimento.

A barreira ao novo, aqui no país, ocorreu com polêmicas de não aceitação nas primeiras publicações intelectuais do NEPEC. $\mathrm{Na}$ fase de difusão das ideias, de pensar e fazer geografia cultural, tal barreira transformou-se 
em convergência de pesquisadores envolvidos na temática. A intolerância era influenciada mais por desconhecimento das ideias do que pelo conteúdo apresentado em geografia cultural. A difusão ocorreu por meio da realização de simpósios, da criação da Revista Espaço e Cultura, da elaboração da série Textos pelo Nepec e da publicação da Coleção Geografia Cultural, pela EdUERJ.

Tais estratégias de difusão das ideias continham como prioridade a fim de preencher a enorme lacuna, tanto na bibliografia dos estudos sobre cultura como nos ensaios, no campo da geografia.

Ao concluir, desejo ressaltar que, nesses 20 anos de NEPEC, acumulei uma lista de pessoas, companheiros, colaboradores, bolsistas, alunos e amigos. Hoje, estamos reunidos no Programa de Extensão em Estudos Avançados em Geografia, Religião e Cultura.

Oxalá a coragem e a dedicação dos doutorandos em estudos do fenômeno da religião e sua espacialidade perdurem por mais vinte anos no NEPEC e na UERJ - no lugar onde se pensam as ideias e se escreve sobre elas.

\section{NOTAS}

${ }^{1}$ Professora Associada do Departamento de Geografia Humana UERJ

Coordenadora do Programa de Estudos Avançados em Geografia, Religião e Cultura -PEAGERC e do Núcleo de Estudos e Pesquisas sobre Espaço e Cultura - NEPEC

\section{REFERÊNCIAS} BIBLIOGRÁFICAS

BERDOULAY, V. A abordagem Contextual. Espaço e Cultura, $\mathrm{n}^{\circ} 16$, p. 47-56, JUL/DEZ de 2003, UERJ, RJ.

BONNEMAISON, J. "Viagem em torno do território". In: CORRÊA, R. L. e ROSENDAHL, Z. (orgs). Geografia Cultural: um século (3), Rio de Janeiro: EdUERJ, 2002, pp. 83-132 [1981].

BÜTTNER, M. et al. "Zur Geschichte und Systematik der Religionsgeographie". In: Geographia Religionum Interdisziplinäre Schrifienreihe zur Religions geographie - Band 2. Berlim: Dietrich Reimer Verlag, 1985, pp. 15-122.

CLAVAL, P. "Le Thème de la religion dan les éhides geographies". Geographie et Cultures. Paris, 1992, nº 2, pp. 85 111.

CORREAA, R. L e ROSENDAHL, Z. A Geografia Cultural no Brasil. Revista da ANPEGE, ano 1, n 1. Curitiba, PR, 2003.

GOMES, P. C. da C. O lugar do olhar: elementos para uma geografia da visibilidade. Rio de Janeiro: Bertrand Brasil, 2013.

HALBACHS, M. La Mémoire Collective. Paris: P.U.F, 1950.

KESSEL, Z. Memória e Memória Coletiva. Site: www.memoriaeducacao.hpg.ig.com.br

LE GOFF, J. História e Memória. 2. Ed, Campinas: Editora da Unicamp, 1996.

NORA, P. Les Sieux de Mémoire. Paris: Gallimard, 1984, v1.

RINSCHEDE, G. Das Pilgerzentrum Lourdes. In: Geographia Religionum, Berlin: Dietrich Reimer Verlag, Band 1, 1985.

ROSENDAHL, Z. Le pouvoir du sacré sur l'espace. Essai d' analyse a partir de diux patits centres brésiliens de pèlerinage: Muquém et Santa Cruz dos Milagres. In: Miteinander, Nebeneinander Gegeneinander. Bochum: Universitätsverlay Dr. N. Brockmeyer, 1994, pp. 115-131.

ROSENDAHL, Z. Espaço e Religião: uma abordagem geográfica. $2^{\circ}$ edição. Rio de Janeiro, UERJ, 2002.

ROSENDAHL, Z. História teria e método em geografia da 
religião. In: Espaço e Cultura, n ${ }^{\circ} 31$, p. 24 - 39. Rio de Janeiro, 2012.

ROSENDAHL, Z. Os Caminhos da Construção Teórica. Ratificando e Exemplificando as Relações entre Espaço e Religião. Geografia Cultural: uma Antologia, v.2. EdUERJ, Rio de Janeiro, 2013.

RUEDA, V. M. S; FREITAS, A; VALLS, V. M. Memória Institucional: uma revisão de literatura. CRB-8 Digital. São Paulo, v. 4, n.1, p. 78-89, abril 2011. Site: http://revista.crb8.org.br;

SATTER, Almir e TEIXEIRA, Renato - Tocando em frente http://letras.mus.br/almir-sater/44082/

SOPHER, D. Geography of Religions. Englewood Cliffs: Prentice Hall, 1967.
SORRE, M. Rencontres de la géographie et la sociologie. Paris. P.U.F. (1957)

TANAKA, H. The Evolution of Pilgrimage: as a spatial-simbolic system. The Canadian Geographer. Toronto, 25, 1981.

VECCHIA, M.J.S.G. A importância do conceito de memória coletiva ou social na visão das ciências sociais. Site: http://nucleotavola.com.br/revista/2011/07/04/a-importancia-doconceito-de-memoria-coletiva-ou-social-na-visao-das-ciencias$\underline{\text { socais/ }}$

WILLIANS, R. Cultura. Tradução de Lólio Lourençço de Oliveira. Rio de Janeiro: Paz e Terra, $3^{\circ}$ edição, 2008. 
PLACE WHERE IDEAS ARE THOUGHT AND WRITES ABOUT THEM: MEMORY - HISTORY NEPEC (1993-2013)

ABSTRACT: THE AIM OF THIS PAPER IS TO CONSTRUCT A MEMORABILIA AND A HISTORY OF THE NEPEC (RESEARCH AND STUDIES GROUP ON (ULTURE AND SPACE). THE GROUP IS LOCATED IN THE GEOGRAPHY INSTITUTE (IG) AT THE STATE UNIVERSITY OF RIO DE JANEIRO (UERJ) AND WAS CREATED IN 1993. THE PAPER REMARKS THREE IMPORTANTS CONTRIBUITIONS OF NEPEC TO BRAZILIAN GEOGRAPHY: THE PIONERISM IN THE DEVELOPMENT OF STUDIES AND RESEARCHS ON RELIGION AND SPACE; THE ROLE AS A DISCLOUSERE CENTER OF INTERNATIONAL CULTURAL GEOGRAPHY; AND THE DIFUSION OF NATIONAL CULTURAL GEOGRAPHY.

KEYWORDS: BRAZILIAN CULTURAL GEOGRAPHY, NEPEC, HISTORY, MEMORY

LUGAR EN QUE PIENSAN LAS IDEAS Y EN EL QUE ESCRIBEN ACERCA DE ELLAS: MEMORIA - HISTORIA NEPEC (1993-2013)

RESUMEN: EL ARTÍCULO CONSTRUYE UN RESCATE DE LA MEMORIA Y LA HISTORIA DEL CENTRO DE ESTUDIOS E INVESTIGACIÓN SOBRE EL ESPACIO Y LA CULTURA, EL NEPEC, ACTIVO EN EL INSTITUTO DE GEOGRAFía DE LA UNIVERSIDAD DEL ESTADO DE RIO DE JANEIRO. EL ARTíCULO ANALIZA EL DESEMPEÑO DE NEPEC DESDE 1993, CUANDO FUE CREADO. DESTACA TRES IMPORTANTES CONTRIBUCIONES A LA NEPEC GEOGRAFÍA BRASILEÑA: UN PIONERO EN EL DESARROLLO DE ESTUDIOS E INVESTIGACIONES SOBRE LA RELIGIÓN EN EL ESPACIO, SU PAPEL COMO CENTRO DE DIFUSIÓN DE LA GEOGRAFía CULTURAL Y SU LUGAR EN LA DIFUSIÓN INTERNACIONAL DE LA GEOGRAFÍA CULTURAL NACIONAL.

PALABRAS CLAVE: GEOGRAFÍA CULTURAL BRASILENA, NEPEC, HISTORIA, MEMORIA 